\title{
Embryonic Stem Cell
}

National Cancer Institute

\section{Source}

National Cancer Institute. Embryonic Stem Cell. NCI Thesaurus. Code C12935.

Embryonic stem (ES) cells are cells derived from the inner cell mass of the early embryo that can be propagated indefinitely in the primitive undifferentiated state while remaining pluripotent. 